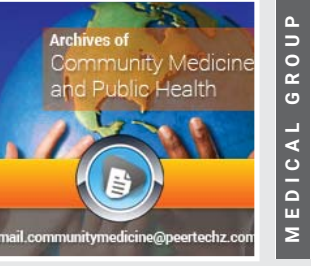

\title{
Self-care Management among Patients with Type 2 Diabetes Mellitus in Tanahun, Nepal
}

\author{
Ishwari Adhikari Baral ${ }^{1 *}$ and Santosh Baral ${ }^{2}$ \\ ${ }^{1}$ Teaching Assistant, Tribhuvan University, Institute of Medicine, Pokhara Nursing Campus, Pokhara, \\ Nepal \\ ${ }^{2}$ General Practitioner, Sunaulo Polyclinic Private Limited, Bhimad Municipality, Tanahun, Nepal
}

Received: 17 December, 2020

Accepted: 03 February, 2021

Published: 04 February, 2021

*Corresponding authors: Ishwari Adhikari Baral, Teaching Assistant, Tribhuvan University, Institute of Medicine, Pokhara Nursing Campus, Pokhara, Nepal, Tel: 9846652411; Email: ishadh@iompnc.edu.np Keywords: Diabetes mellitus; Self-care practice; SDSCA; Diabetic patients

https://www.peertechz.com

\section{Check for updates}

\begin{abstract}
Background: Globally, poor adherence to self-care practices in diabetic patients persist as major challenges with respect to public health concern. Maintaining optimum blood glucose level in diabetic patients requires proper self-care management focusing on diet, medication, regular exercise, and foot care. The aim of the study was to investigate self-care practices and predictors of self-care management activities among type 2 diabetes mellitus patients in Tanahun district of Nepal.

Methods: Descriptive cross- sectional study was carried out among 139 patients with type 2 diabetes mellitus attending outpatient department of two private polyclinics of Bhimad Municipality at Tanahun district, Nepal. The self-care practice was measured by the Summary of Diabetes Self-Care Activities (SDSCA). Predictors of self-care behaviors were identified by using binary logistic regression.

Results: Among the 139 patients, less than half (46\%) had desirable self-care practice for diabetes management. Of the total, $89.9 \%$ had adequate exercise and $74.8 \%$ and had foot care management practices. The multivariate analysis showed that poor self-care practice was likely to occur among illiterate patients $(\mathrm{AOR}=2.950 ; 95 \% \mathrm{Cl}=$ (1.149-7.573); $\mathrm{p}<0.05)$ and patients with co-morbidities ( $\mathrm{AOR}=2.801 ; 95 \% \mathrm{Cl}=1.121-7.002 ; \mathrm{p}<0.05)$

Conclusion: Self-care practice of diabetic participants was considerably particularly in practice of recommended blood glucose testing. These findings recommend health care organizations and professionals to plan on behavioral change communication and education programs targeting diabetic patients in order to improve their self-care practice.
\end{abstract}

\section{Introduction}

Diabetes Mellitus, a 'silent disease' with minimal symptoms at the beginning has rapid progression until target organ damage and with its serious consequences, it has become an important public health concern. In order to achieve and maintain optimum blood glucose level, diabetic patients need good self-care management [1]. Worldwide, number of people diagnosed with diabetes mellitus has increased by about four times from 108 million in 1980 to 422 million in 2014. In the year 2014, diabetes caused 4.9 million deaths and has been most important cause of kidney diseases, eye complications, cerebrovascular accident, cardiac failure, and amputation [2].

In the recent years, prevalence of diabetes has increased more rapidly in developing countries than in developed countries. The 2016 diabetic profile reported that $9.1 \%$ Nepalese are diagnosed with diabetes; among which $10.5 \%$ are men and $7.9 \%$ comprise women [3]. A high percentage of the world's diabetes cases belong to Type 2 Diabetes (T2D) with modifiable risk factors such as unhealthy diet, being obese or overweight, sedentary lifestyle, and smoking. These factors can be modified through behavioral and environmental changes [4]. Adequate self-care practices in terms of diet, medication, and exercise help in maintaining normal level of blood glucose in patients with diabetes. Moreover, regular foot-care practice helps to protect against diabetic foot ulcers and amputation [5].

The diabetes self-care includes the home-based activities such as eating healthy diet, proper exercise, adherence to medication and preventive care against foot ulcer and other complications [6]. Diabetic patients' own care practice helps to enhance their quality of life and prevents the complications involving heart, blood vessels, eyes, kidneys, and nervous system $[6,7]$. 
However, growing literature suggest that patients with diabetes do not perform required care activities by themselves. A study done among Philipino-American adults with diabetes mellitus concluded that less number of younger adults would perform optimum self-care behavior concerning to diet, medication and monitoring of blood glucose and suggested increased risk of diabetes related comorbidities and complications in younger adults whereas older adults and females were more likely to follow the medication regimens and evenly space carbohydrate intake as recommended by the health care practitioners. Furthermore, males and adults with higher education were involved in exercising frequently [8].

Many studies regarding diabetes self-care and adherence to medication are focused in developing countries. A study done in Ethiopia reported that about $60 \%$ patients had poor glycemic control as only $15.1 \%$ had adequate practice in blood glucose monitoring. Predictors of poor self-care behaviors were males, patients living in rural area, those with diabetes duration less than six years, those with no accessibility for self-testing of blood sugar and having poor knowledge about diabetes [9]. Similar study done in another state of Ethiopia revealed that 45.5\% patients scored below the mean in SDSCA tool. Having knowledge on diabetes, secondary school education and having diabetes for longer duration were the significant predictors of adequate self-care management practice among diabetic adults [10].

In Nepal where there was higher prevalence of communicable disease in previous decades, at present there is epidemiological transition to increased prevalence of Non-Communicable Diseases (NCD) along with growing prevalence of type 2 diabetes mellitus [11]. Knowledge on diabetes, adequate selfcare behavior and adherence to diabetic medications could be beneficial for prevention, early detection of diabetes cases, decreased complications which would improve the quality of life of individuals affected by diabetes [5]. Various studies in Nepal suggest that diabetic patients have poor knowledge and practice regarding self-care activities. A study in Biratnagar revealed inadequate practice of self-care among $50 \%$ diabetic patients attending the tertiary care hospital. The most frequently implemented self-care activity was foot care whereas testing of blood sugar was least performed [12]. Furthermore, diabetes self-care was significantly associated with age of the diabetic patient, their education level, occupation of the patients and age at diagnosis of diabetes.

Another study done among 192 diabetic patients to identify their self-care management practice highlighted that 31.77\% adults had poor knowledge whereas $57.29 \%$ had average knowledge and only $10.93 \%$ had good knowledge of diabetes mellitus. Patients most frequently practiced care of their limbs, exercise, as well as regular health checkup. However, greater than two third of patients had uncontrolled blood sugar [6]. This study also revealed that though the patients had known that performing regular self-care could decrease the diabetes related complications, they are irregular in performing the self-care practices [6]. Another study done in a tertiary level hospital in Kathmandu revealed that poor self-care adherence was associated with poor blood sugar control among diabetic patients. Thus, this study recommended for promoting integrated knowledge with health education on diabetes management to the communities in order to improve glycemic control [13].

Poor self-care management worsens the clinical parameter with poor glycemic control leading to undesirable patient outcome and only permits suboptimal effect of the treatment. However, to the researchers' knowledge, there are no studies in Nepal measured by SDSCA tool to identify the self-care practice among diabetic patients in regards to different selfcare domains. Therefore, researcher felt the immense need for assessment of self-care management practices with significant advantage to diabetic patient's adherence in disease treatment as well as reducing the adverse effects associated with disease spectrum. This study was conducted with the objective to assess the self-care management practices of patients with type 2 diabetes mellitus and to identify predictors of self-care management activities among patients with diabetes mellitus.

\section{Theoretical perspective on self-care management prac- tice}

Diabetic patients have to carry out their daily selfmanagement activities according to the instruction of their health care provider in order to prevent diabetes-related morbidity and mortality. In diabetes care, self-management by patients is the key basis which is believed to enhance patients' efficacy in diabetes management by increasing disease awareness and improving prevention [14]. However, patients' self-care management practice depends upon the health belief of the patient towards their disease. Health belief model helps to understand how a diseased person prioritizes to follow the specific health action when he perceives himself at risk and feels that this behavior is beneficial to prevent the complication and promote early recovery [15]. In case of diabetic patients, having knowledge about the diabetic selfcare practice and health action such as management of diet, exercise, compliance to the medicines, foot care, regular blood glucose testing and glycemic control as well as behavioral changes like smoking and alcohol cessation are the particular health actions which would prevent the diabetic related complications and promote their normal wellbeing. Moreover, self-care compliance and improvement and minimizing the barriers for self-care is possible by focusing on diabetic care education and support programs related to promotion of selfmanagement activities to the targeted population [13]. Based on the health belief model, this study assesses the knowledge based self-care management practice of the diabetic patients in terms of maintaining adequate diet, physical activity, medication adherence, blood sugar monitoring, diabetic foot care and smoking status.

\section{Materials and methods}

\section{Study design, settings, and participants}

A descriptive cross-sectional study was carried out for six months period between April and October 2019 in two private polyclinics of Bhimad Municipality, Tanahun Nepal- 
Sunaulo polyclinic and Bhimad Polyclinic. Bhimad is located in Tanahun district, Gandaki Province. It is $40 \mathrm{~km}$ (1 hour 30 mins vehicle distance) far from Pokhara Metropolitan city. Though the polyclinics are located in municipality, most of the patients who come for the treatment here are from the rural areas of Tanahun district. Furthermore, the selected clinics are the two major clinics where majority of diabetic patients come for their treatment and follow up and they visit Pokhara city only in case of complications. The setting was purposively chosen because majority of the studies regarding self-care management among patient diagnosed with diabetes are centralized to the diabetic clinics situated in urban areas like Pokhara and thus studies revealing diabetes self-care practice in rural areas is lacking. Therefore, researcher is interested to find out the selfcare management practices of diabetic patients in rural areas.

A non- probability consecutive sampling technique was used for the study. All the patients 20 years and above who were diagnosed with diabetes mellitus for at least one year were interviewed. Sample size was 139 according sample size estimation formula $(\mathrm{n})=\mathrm{Z} 2 \mathrm{pq} / \mathrm{l}^{2}[$ where $\mathrm{z}=$ statistic corresponding to level of confidence, $\mathrm{p}=$ disease prevalence, $\mathrm{q}=1-\mathrm{p}$ and $\mathrm{l}=$ allowable error at $95 \%$ confidence interval $]$. According to literature searched, type 2 diabetes prevalence in Nepal is $9.1 \%$ [16]. Thus, taking $\mathrm{p}=9.1 \%=0.091, \mathrm{q}=0.909$, $\mathrm{l}=5 \%=0.05$ at $95 \%$ confidence interval ; calculated sample size was $1.96 \times 1.96 \times 0.091 \times 0.909 / 0.0025=127$. Adding $10 \%$ nonresponse rate, final sample size was $(127+12)=139$.

\section{Data collection instrument and method}

Interviewer administered questionnaire was used for the data collection which consisted of two parts. Part I included sociodemographic information and anthropometric measurements. Part II included standard questionnaire- the Summary of Diabetes Self-Care Activities (SDSCA). This standard tool was developed by Toobert, Hampson and Glassgow [17] to measure the self-care activities used by diabetic patients. It consists of seven domains- dietary pattern, exercise, compliance to medication, foot care, testing of blood glucose and status of smoking among diabetic patients. Literatures suggest SDSCA as a reliable and valid tool $[18,19]$. In order to maintain the content validity, the tool was developed according to objectives of the study through broad literature review and consultation with subject experts. Moreover, for the use of SDSCA tool in Nepalese context, back-to-back translation of the tool was done. Firstly, English to Nepali translation and secondly Nepali to English translation was done by two different bilingual translators. This strategy also helped to maintain content validity of the instrument. In order to identify consistency, clarity and accuracy of the tool, pretesting of the instrument was conducted on 13 diabetic patients who came for regular health checkup in Shuvalaxmi polyclinic in Tanahun district and who met the sample criteria. Reliability was tested by calculating Cronbach's alpha value 0.776 which showed high internal consistency.

Study was carried out after the approval of research proposal from Tribhuvan University Institutional Review Board. Before data collection, the request letter for data collection was sent to the polyclinics for permission to conduct the research. Concerned authorities were briefed about the objectives, process, and importance of the study. Informed written consent with all the information was obtained from the patients prior to the data collection. After their OPD checkup, patients were called in a separate room and were interviewed. The patients were benefited by informal health teaching about the selfcare management. In average, time taken for the interview was about 20-25 minutes. The obtained data was used for the research purpose only.

\section{Data management and statistical analysis}

The data was entered into the Epi-data software and was analyzed using SPSS version 16. Diabetic patients' regularity of self-care activity in last seven days for all four domains diet, exercise, food-care and blood glucose testing was measured. For each domain mean number of days of self-care was calculated. The overall mean score for care activities in different domains was determined by summation of the mean score of all domains and dividing it by the sum of number of questions on each scale of these domains. As the overall mean score was 3.5, final classification was done as having desirable or adequate self-care practice if the score is $\geq 3.5$ whereas the score of $<3.5$ was categorized as poor or inadequate self-care practice [9].

At first bivariable analysis as appropriate for categorical variables (chi-square test) was done to identify the significant association between different variables along with the odds ratio. Furthermore, the significant independent variables $(p<0.05)$ were again analyzed by using multivariable analysis (binary logistic regression) to identify the independent predictors of inadequate practices of self-care among the patients with diabetes. For the analysis, $5 \%$ level of significance was considered with $\mathrm{p}$ - value $<0.05$ and confidence interval at 95\%. Hosmer and Lemeshow test for the final mode showed fitness of model.

\section{Results}

\section{Socio demographic and clinical characteristics of the patients}

Of the total patients $(\mathrm{n}=139)$ having mean age of 50.9 years (ranging from 39 to 82 years), $66.2 \%$ were males. Furthermore, $60.4 \%$ belonged to the disadvantaged ethnic group (Janajati/ Dalit). Most (96.4\%) were married while $64.0 \%$ were literate. Moreover, $69.8 \%$ were employed and $59.7 \%$ were rural residents. Comorbidities were present in $45.3 \%$ patients among which $65.1 \%$ had hypertension. Duration of diabetes was less than five years among $65.6 \%$ of the participants. Majority $(81.3 \%)$ were under medication. More than half $(51.8 \%)$ had normal BMI. Majority (79.1\%) did not smoke on past seven days (Table 1).

\section{Self-care management practice of the patients}

Regarding the self-care practice, less than half ( $46 \%)$ had desirable self-care practice for diabetes management. Amongst the various domains of self-care, $67.6 \%$ have adequate dietary 
Table 1: Socio-demographic and Clinical Characteristics of the Patients $(n=139)$ Background Characteristics Frequency Percentage

Age

\begin{tabular}{|c|c|c|}
\hline $20-39$ & 23 & 16.5 \\
\hline $40-59$ & 87 & 62.6 \\
\hline $\begin{array}{c}60 \text { and above } \\
\text { Mean age } 50.95 \pm 10.41(32-82)\end{array}$ & 29 & 20.9 \\
\hline \multicolumn{3}{|l|}{ Sex } \\
\hline Male & 92 & 66.2 \\
\hline Female & 47 & 33.8 \\
\hline \multicolumn{3}{|l|}{ Ethnicity/caste } \\
\hline Brahmin/Chettri & 55 & 39.6 \\
\hline Janajati/Dalit & 84 & 60.4 \\
\hline \multicolumn{3}{|l|}{ Marital Status } \\
\hline Married & 134 & 96.4 \\
\hline Single (never married, widow/widower) & 5 & 3.6 \\
\hline \multicolumn{3}{|l|}{ Educational Status } \\
\hline Literate & 89 & 64.0 \\
\hline Illiterate & 50 & 36.0 \\
\hline \multicolumn{3}{|l|}{ Employment Status } \\
\hline Employed & 97 & 69.8 \\
\hline Unemployed & 42 & 30.2 \\
\hline \multicolumn{3}{|l|}{ Place of Residence } \\
\hline Urban & 56 & 40.3 \\
\hline Rural & 83 & 59.7 \\
\hline \multicolumn{3}{|l|}{ Monthly Income } \\
\hline Less than 10000 & 26 & 18.7 \\
\hline 10000 and more & 113 & 81.3 \\
\hline \multicolumn{3}{|l|}{ Comorbidities } \\
\hline Yes & 63 & 45.3 \\
\hline No & 76 & 54.7 \\
\hline \multicolumn{3}{|l|}{ If yes $(n=63)$} \\
\hline Hypertension & 41 & 65.1 \\
\hline Others & 22 & 34.9 \\
\hline \multicolumn{3}{|l|}{ Year of diagnosis } \\
\hline Less than 5 years & 91 & 65.5 \\
\hline 5 years and more & 48 & 34.5 \\
\hline \multicolumn{3}{|l|}{ Taking medications } \\
\hline Yes & 113 & 81.3 \\
\hline No & 26 & 18.7 \\
\hline \multicolumn{3}{|l|}{ If yes, (113) } \\
\hline Oral hypoglycemic agents & 98 & 86.7 \\
\hline Insulin & 4 & 3.6 \\
\hline Both & 11 & 9.7 \\
\hline \multicolumn{3}{|l|}{ BMI } \\
\hline 18.5-25 (normal) & 72 & 51.8 \\
\hline 26-30 (overweight) & 52 & 37.4 \\
\hline More than 30 (obese) & 15 & 10.8 \\
\hline \multicolumn{3}{|l|}{ Smoking status on past seven days } \\
\hline Yes & 29 & 20.9 \\
\hline No & 110 & 79.1 \\
\hline
\end{tabular}

plan. Majority $(89.9 \%)$ and $(74.8 \%)$ of the diabetic patients have adequate exercise and foot care practice, respectively (Table 2).

\section{Predictors of diabetes self-care practice of the patients}

The chi square test showed the statistically significant association of self-care practice with sex $(\mathrm{p}<0.05)$, ethnicity $(\mathrm{p}<0.01)$, educational status $(\mathrm{p}<0.01)$, place of residence $(\mathrm{p}<0.01)$, monthly income $(\mathrm{p}<0.01)$ and presence of comorbidities $(\mathrm{p}<0.01)$ (Table 3$)$. The binary logistic regression analysis showed that poor self-care practice was likely to occur among illiterates patients $(\mathrm{AOR}=2.950 ; 95 \% \mathrm{CI}=(1.149-7.573)$; $\mathrm{p}<0.05$ ) and patients with co-morbidities (AOR $=2.801 ; 95 \%$ $\mathrm{CI}=1.121-7.002 ; \mathrm{p}<0.05$ ) (Table 3).

\section{Discussion}

Patients with diabetes are often recommended to follow healthful living with regular self-care practices in diet, exercise, care of foot and regular blood glucose monitoring. This study revealed that among 139 diabetic patients, 54\% have poor practice of self-care for the management of their diabetic status. Findings correspond with the study done in Biratnagar, Nepal where $49.6 \%$ participants had poor self-care practice. Study done in Harrari, Ethiopia also revealed that $60.8 \%$ patients follow poor self-care practice [20].

However, study finding is higher than in the three different studies conducted in Ethiopia where, 45.5\% [10], 45.7\% [21] and $39.3 \%$ [9] patients had poor practice of diabetes self-care. This might be because of the small sample size and different setting in our study which is a rural area with no easier access to health-related activities. In rural areas, different barriers are recognized which limit the diabetic self-care activities in developing countries such as no access to better health care service, expensive medication cost, poor relationship between patient and health-care provider, higher degree of symptoms and health care providers distributed unevenly in urban and rural areas [14].

In this study, multivariate analysis showed that illiterate patients were three times more likely to perform poor self-care activities than literate patients. This finding is consistent with the study done in Ethiopia where uneducated diabetic patients were 3.6 times more likely to perform undesirable care activities than educated patients [21]. The finding also corresponds with other studies done in Harrari [20] and North-West Ethiopia [22]. The possible reason for this might be that educated persons have increased interest on their health promotion for which they become aware and follow the desirable self-care

Table 2: Self Care Management Practice of the Patients $(n=139)$.

\begin{tabular}{|c|c|c|}
\hline \multirow{2}{*}{ Self Care Activities } & Adequate & Inadequate \\
\cline { 2 - 3 } & No. (\%) & No. (\%) \\
\hline Total Self care & $64(46)$ & $75(54)$ \\
\hline Diet & $94(67.6)$ & $45(32.4)$ \\
\hline Exercise & $125(89.9)$ & $14(10.1)$ \\
\hline Footcare & $104(74.8)$ & $35(25.2)$ \\
\hline Blood glucose testing & $2(1.4)$ & $137(98.6)$ \\
\hline
\end{tabular}


Table 3: Predictors of Diabetes Self-care Practice of the Patients.

\begin{tabular}{|c|c|c|c|c|c|}
\hline \multirow{2}{*}{ Characteristics } & \multicolumn{2}{|c|}{ Self care practice } & \multirow[b]{2}{*}{ COR $(95 \% \mathrm{CI})$} & \multirow[b]{2}{*}{ AOR $(95 \% \mathrm{Cl})$} & \multirow{2}{*}{$\begin{array}{c}\text { p- } \\
\text { value }\end{array}$} \\
\hline & Adequate & Inadequate & & & \\
\hline \multicolumn{6}{|l|}{ Sex } \\
\hline Male & $49(53.3 \%)$ & $43(46.7 \%)$ & 1 & 1 & \\
\hline Female & $15(31.9 \%)$ & $32(68.1 \%)$ & $2.431(1.163-5.082)$ & $1.437(0.578-3.569)$ & 0.435 \\
\hline \multicolumn{6}{|l|}{ Ethnicity } \\
\hline Brahmin/chhetri & $36(65.5 \%)$ & $19(34.5 \%)$ & 1 & 1 & \\
\hline Janajati/dalit & $28(33.3 \%)$ & $56(66.7 \%)$ & $3.789(1.849-7.765)$ & $1.229(0.412-3.672)$ & 0.711 \\
\hline \multicolumn{6}{|l|}{ Educational Status } \\
\hline Literate & $54(60.7 \%)$ & $35(39.3 \%)$ & 1 & 1 & \\
\hline Illiterate & $10(20.0 \%)$ & $40(80.0 \%)$ & $6.171(2.737-13.915)$ & $2.950(1.149-7.573)$ & $0.024 *$ \\
\hline \multicolumn{6}{|l|}{ Place of Residence } \\
\hline Urban & $35(62.5 \%)$ & $21(37.5 \%)$ & $3.103(1.534-6.278)$ & $1.437(0.519-3.984)$ & 0.486 \\
\hline Rural & $29(34.9 \%)$ & $54(65.1 \%)$ & 1 & 1 & \\
\hline \multicolumn{6}{|l|}{ Income } \\
\hline < Rs 10000 & $5(19.2 \%)$ & $21(80.8 \%)$ & 1 & 1 & \\
\hline Rs 10000 and above & $59(52.2 \%)$ & $54(47.8 \%)$ & $0.218(0.077-0.618)$ & $2.032(0.504-8.197)$ & 0.319 \\
\hline \multicolumn{6}{|l|}{ Comorbidities } \\
\hline Yes & $15(23.8 \%)$ & $48(76.2 \%)$ & $0.172(0.082-0.363)$ & $2.801(1.121-7.002)$ & $0.028 *$ \\
\hline No & $49(64.5 \%)$ & $27(35.5 \%)$ & 1 & 1 & $0.0 \angle 0^{\wedge}$ \\
\hline
\end{tabular}

practice [21]. Findings also revealed that patients with comorbidities were 2.8 times more likely to follow inadequate self-care behavior than those without co-morbidities. A study done from West Ethiopia also suggested consistent finding [9].

Various studies suggest gender differences in reporting the self-management behavior in diabetic patients. Present study finding also revealed that females were 2.4 times more liable to have poor self-care practice than males. This finding was similar to study done in Pokhara, Nepal which revealed that women had low efficacy with respect to diabetes self-care (35\%) in comparison to men (65\%) [23]. The reason for this might be because of the gender difference in social structure which brings difference in lifestyle modification like exercise, medication compliance and other care behavior. Thus, there is immense need to formulate gender specific behavior change communication strategies for improvement of self-care management practice of patients with diabetes.

The diabetic patients' living places also revealed significant association with undesirable self-care behaviour. Diabetic patients residing in rural areas were 3.1 times more likely to perform poor self-care activities than those residing in urban areas. Similar finding was reported from the studies in West Ethiopia [9], North Ethiopia [24] and Bangladesh [25].

\section{Conclusion}

In conclusion, findings of the present study showed considerably poor self-care practice among adult diabetic patients. Particularly, diabetic patients were not consistent in regular monitoring of their blood glucose level as recommended. Predictors of inadequate self-care behaviour were illiteracy and having comorbidities. Moreover, diabetic females and those living in rural areas also had poor practice of self-care in diabetes control. These findings highlighted that diabetic patients need intervention with integrated approach through treatment as well as health education which will increase health and wellbeing of the patients. Health care organizations and health professionals should focus on behavioral change communication programs to diabetic patients which must be gender specific and according to locality whether the patients belong to urban or rural residents. Strategic approach to health literacy focusing on rural residents would be more beneficial. Since self-care regarding blood glucose testing is poor, provision of self-monitoring glucometer for needy patients seem essential.

\section{References}

1. Kassahun T, Gesesew H, Mwanri L, Eshetie T (2016) Diabetes related knowledge, self-care behaviours and adherence to medications among diabetic patients in Southwest Ethiopia: a cross-sectional survey. BMC Endocr Disord 16: 28. Link: https://bit.ly/2MPZrep

2. World Health Organization (2018). Diabetes Key facts. Link: https://bit.ly/3tlPR3B

3. HERD International (2018) Diabetes in Nepal. Link: https://bit.ly/3tlDg0a

4. World Health Organization (2016). Global Report on Diabetes. Link https://bit.ly/2MRTehL

5. Basu S, Garg S, Sharma N, Singh MM, Garg S (2018) Adherence to selfcare practices, glycemic status and influencing factors in diabetes patients in a tertiary care hospital in Delhi. World J Diabetes 9: 72-79. Link: https://bit.ly/3tgFrlT

6. Chaurasia N, Mishra R, Ling H, Thapa B, Pokhrel A, et al. (2015) A selfcare management awareness study among diabetes mellitus patients in rural Nepal. American Journal of Public Health Research 3: 67-71. Link: https://bit.ly/3j9jyAg

7. Adibe MO, Aguwa CN, Ukwe CV, Okonta JM, Udeogaranya OP (2009) Diabetes self-care knowledge among type 2 diabetic outpatients in south-eastern Nigeria. Int J Drug Dev Res 1: 85-104. Link: https://bit.ly/3tmV4IA

8. Jordan DN, Jordan JL (2010) Self-care behaviors of Filipino-American adults with type 2 diabetes mellitus. Journal of Diabetes and its Complications 24 : 250-258. Link: https://bit.ly/3rkRywa 
9. Dedefo MG, Ejeta BM, Wakjira GB, Mekonen GF, Labata BG (2019) Self-care practices regarding diabetes among diabetic patients in West Ethiopia. BMC Res Notes 12: 212. Link: https://bit.ly/2Lc4Hs6

10. Gurmu Y, Gela D, Aga F (2018) Factors associated with self-care practice among adult diabetes patients in West Shoa Zone, Oromia Regional State, Ethiopia. BMC Health Serv Res 18: 732. Link: https://bit.ly/3rmq4GN

11. Gyawali B, Sharma R, Neupane D, Mishra SR, van Teijlingen E, et al. (2015) Prevalence of type 2 diabetes in Nepal: a systematic review and meta-analysis from 2000 to 2014. Glob Health Action 8: 29088. Link: https://bit.ly/3jaDiUb

12. Thapa D (2018) Self-care activities among patients with diabetes attending a tertiary care hospital in Biratnagar, Nepal. Journal of Nobel Medical College 7 : 11-7. Link: https://bit.ly/2MPZ03L

13. Pokhrel S, Shrestha S, Timilsina A, Sapkota M, Bhatt MP, et al. (2019) Self-care adherence and barriers to good glycaemic control in Nepalese type 2 diabetes mellitus patients: a hospital-based cross-sectional study. J Multidiscip Healthc 12: 817-826. Link: https://bit.ly/2NSuyX0

14. Shrivastava SR, Shrivastava PS, Ramasamy J (2013) Role of self-care in management of diabetes mellitus. J Diabetes Metab Disord 12: 14. Link: https://bit.ly/2MPYXVD

15. Jalilian F, Motlagh FZ, Solhi M, Gharibnavaz H (2014) Effectiveness of self-management promotion educational program among diabetic patients based on health belief model. J Educ Health Promot 3: 14. Link: https://bit.ly/2Mm3Rda

16. Baral S, Upreti S, Lamichhane B (2016) Diabetes in Nepal. HERD International Link: https://bit.ly/3tfREHk

17. Toobert DJ, Hampson SE, Glasgow RE (2000) The summary of diabetes selfcare activities measure: results from 7 studies and a revised scale. Diabetes care 23: 943-950. Link: https://bit.ly/3azKqWm
18. Bujang MA, Ismail M, Bariyyah NK (2016) Validation of the summary of diabetes self-care activities (SDSCA) in Malay language for Malaysian adults. MJPHM 16: 227-234. Link: https://bit.ly/3axFctU

19. Kamradt M, Bozorgmehr K, Krisam J, Freund T, Kiel M, et al. (2014) Assessing self-management in patients with diabetes mellitus type 2 in Germany: validation of a German version of the Summary of Diabetes Self-Care Activities measure (SDSCA-G). Health Qual Life Outcomes 12: 185. Link: https://bit.ly/39IWHIQ

20. Ayele K, Tesfa B, Abebe L, Tilahun T, Girma E (2012) Self-care behavior among patients with diabetes in Harari, Eastern Ethiopia: the health belief model perspective. PloS One 7: e35515. Link: https://bit.ly/2YEc7Yn

21. Chali SW, Salih MH, Abate AT (2018) Self-care practice and associated factors among Diabetes Mellitus patients on follow up in Benishangul Gumuz Regional State Public Hospitals, Western Ethiopia: a cross-sectional study. BMC Res Notes 11: 833. Link: https://bit.ly/3oNg3At

22. Aschalew AY, Yitayal M, Minyihun A, Bisetegn TA (2019) Self-care practice and associated factors among patients with diabetes mellitus on follow up at University of Gondar Referral Hospital, Gondar, Northwest Ethiopia. BMC Res Notes 12: 591. Link: https://bit.ly/2MMlaTe

23. Shrestha AD, Kosalram K, Gopichandran V (2013) Gender difference in care of type 2 diabetes. Journal of the Nepal Medical Association 52. Link: https://bit.ly/3tjUlHX

24. Niguse H, Belay G, Fisseha G, Desale T, Gebremedhn G (2019) Self-care related knowledge, attitude, practice and associated factors among patients with diabetes in Ayder Comprehensive Specialized Hospital, North Ethiopia. BMC Res Notes 12: 34. Link: https://bit.ly/2MMupnl

25. Rahaman KS, Majdzadeh R, Naieni KH, Raza O (2017) Knowledge, Attitude and Practices (KAP) regarding chronic complications of diabetes among patients with type 2 diabetes in Dhaka. International Journal of Endocrinology and Metabolism 15. Link: https://bit.ly/3ricfJe

\footnotetext{
Discover a bigger Impact and Visibility of your article publication with Peertechz Publications

\section{Highlights}

* Signatory publisher of ORCID

* Signatory Publisher of DORA (San Francisco Declaration on Research Assessment)

* Articles archived in worlds' renowned service providers such as Portico, CNKI, AGRIS, TDNet, Base (Bielefeld University Library), CrossRef, Scilit, J-Gate etc.

* Journals indexed in ICMJE, SHERPA/ROMEO, Google Scholar etc.

* OAI-PMH (Open Archives Initiative Protocol for Metadata Harvesting)

* Dedicated Editorial Board for every journa

* Accurate and rapid peer-review process

* Increased citations of published articles through promotions

- Reduced timeline for article publication

Submit your articles and experience a new surge in publication services (https://www.peertechz.com/submission).
}

Peertechz journals wishes everlasting success in your every endeavours.

Copyright: @ 2021 Adhikari Baral I, et al. This is an open-access article distributed under the terms of the Creative Commons Attribution License, which permits unrestricted use, distribution, and reproduction in any medium, provided the original author and source are credited. 